\section{O CONTRIBUTO DA EDUCAÇÃO FÍSICA PARA A FORMAÇÃO DE INDIVÍDUOS FISICAMENTE CULTOS: UMA PERSPETIVA PORTUGUESA}

\author{
THE CONTRIBUTION OF PHYSICAL EDUCATION TO THE TRAINING \\ OF PHYSICALLY EDUCATED INDIVIDUALS: A PORTUGUESE \\ PERSPECTIVE
}

\author{
LAS APORTACIONES DE LA EDUCACIÓN FÍSICA PARA LA \\ FORMACIÓN DE INDIVIDUOS FÍSICAMENTE CULTOS: UNA \\ PERSPECTIVA PORTUGUESA
}

\section{Elsa Maria Ferro Ribeiro-Silva*, Luís Marcel Valenzuela Contreras**, Nuno Serra Pacheco Mendes*}

\begin{abstract}
Palavras chave: Aprendizagem. Educação Física. Prática profissional. Exercício físico.

Resumo: Este trabalho, realizado com 150 indivíduos no final da escolaridade obrigatória e candidatos a uma licenciatura em Ciências do Desporto, pretende perceber se a Educação Física está a contribuir para a formação de indivíduos fisicamente cultos. Seguimos uma metodologia quantitativa e optámos por um questionário com três partes: a primeira de questões fechadas e de caracterização sociodemográfica da amostra; a segunda, também de questões fechadas, sobre o entendimento acerca das Finalidades da Educação Física; e a terceira composta por 25 afirmações de escolha dicotómica (verdadeiro/falso), sobre conteúdos fundamentais para uma prática autónoma de atividade física, constantes nos Programas Nacionais de Educação Física (Currículos Nacionais) para o ensino secundário. Os resultados revelam fragilidades nos conhecimentos dos indivíduos relativamente ao desenvolvimento das capacidades motoras, aos efeitos da prática de exercício físico, a procedimentos de segurança e à composição e funcionamento corporal, afastando-se do preconizado por aqueles Programas Nacionais.
\end{abstract}

Keywords: Learning. Physical Education. Professional practice. Exercise.

Palabras clave: Aprendizaje. Educación Física. Práctica profesional. Ejercicio físico.
Abstract: This study was carried out with 150 male students at the end of their mandatory education and with candidates to a degree in Sports Science and Physical Education. It aims to understand if Physical Education contributed to the education of physically educated individuals. We followed a quantitative methodology and administered a three-part questionnaire: close-ended questions for the sociodemographic characterization of the sample; close-ended questions on participants' understanding of the purposes of Physical Education; true-or-false questions on fundamental contents for an autonomous practice of physical activity, which are included in the National Curricula of Physical Education for secondary school. The results reveal individuals' weak knowledge of motor skills development, effects of physical exercise, safety procedures, and body composition and functioning, which is not in accordance with National Curricula.

Resumen: Este trabajo, realizado con 150 estudiantes al final de su escolaridad obligatoria y aspirantes a cursar la licenciatura en Ciencias del Deporte, pretende averiguar si la Educación Física está contribuyendo con la formación de individuos físicamente cultos. Seguimos una metodología cuantitativa y optamos por un cuestionario con tres partes: la primera con cuestiones cerradas y de caracterización sociodemográfica de los participantes; la segunda, también con cuestiones cerradas y sobre su entendimiento acerca de las finalidades de la Educación Física; y la tercera, compuesta por 25 afirmaciones de selección dicotómica (verdadero y falso), sobre contenidos fundamentales para una práctica autónoma de la actividad física y que constan en los Programas Nacionales de Educación Física (Currículos Nacionales) para el bachillerato. Los resultados revelan fragilidades en los conocimientos de los participantes en lo referente al desarrollo de las capacidades motoras, los efectos de la práctica de ejercicio físico, los procedimientos de seguridad y la composición y funcionamiento corporal, alejándose de lo preconizado en aquellos Programas Nacionales.
*Universidade de Coimbra. Coimbra. Portugal. E-mail: elsasilva@fcdef.uc.pt; nunopachecomendes@hotmail.com

**Universidad Católica Silva Henríquez. Santiago. Chile. E-mail: Ivalenz@ucsh.cl

Recebido em: 16-07-2019 Aprovado em: 08-06-2020 Publicado em: 27-06-2020 


\section{INTRODUÇÃO}

Não negando que a obesidade é um dos desafios à escala mundial, mais importantes do século XXI (WORLD HEALTH ORGANIZATION, 2013), estamos convictos que tal tem empurrado para a Educação Física, frequentemente com a complacência dos seus profissionais e mesmo das políticas educativas, a responsabilidade de resolver ou de controlar aquele problema, partindo da convicção de que o exercício físico, por si só, leva à redução do peso, apesar dos vários estudos que o contradizem (MALHOTRA, NOAKES; PHINNEY, 2015; GARD; WRIGHT, 2005; CAMPOS, 2004).

Reforçando as correntes biologistas, ou tão só os interesses económicos por detrás deste "pânico" sobre a obesidade e as doenças que lhe estão associadas, esta enfatização da saúde, do combate ao sedentarismo e do controlo da obesidade está, sub-repticiamente, a conquistar terreno ao objetivo pedagógico da Educação Física.

De acordo com Graça (2012), a dramatização do sedentarismo e da obesidade em idades infantis reivindica uma maior centralidade do exercício orientado para a saúde e um melhor aproveitamento do tempo da Educação Física para proporcionar maior dispêndio energético e fomentar hábitos de atividade física e um estilo de vida saudável, o que se revela impossível face à curta duração e intensidade do esforço naquelas aulas e ao limitado número de sessões semanais, quase sempre concentrados em dois dias.

Ainda mais críticos são Moreno-Doña; Rivera-Garcia e Trigueros-Cervantes (2014), que, manifestando a sua oposição à alteração da designação da disciplina de Educação Física para Educação Física e Saúde, no Chile, afirmaram: "[...] son los profesores de EF quienes, gracias al aumento a cuatro horas de clase, deben obrar el milagro de transformar la grasa en músculo y la obesidade en delgadez [...]"

Esta pressão que a Educação Física vem, cada vez mais, sofrendo no sentido da saúde, tende a instrumentalizá-la para finalidades relacionadas com o cuidado e controlo do corpo, afastando-a da perspetiva pedagógica e colocando-a numa posição de vulnerabilidade, ao responsabilizá-la por algo que dificilmente poderá garantir. (BATISTA; QUEIRÓS, 2015).

\subsection{EDUCAÇÃO FÍSICA E O NÃO-ENSINO}

As redes sociais, os jogos de computador e as conversas por WhatsApp, levam a que as crianças e os jovens façam cada vez menos exercício físico (ARÉVALO; HERNANDO; MON, 2014; BATISTA; QUEIRÓS, 2015) dada a facilidade com que comunicam e interagem com o seu círculo de amizades a partir do seu quarto.

Contudo, na visão de Arévalo, Hernando e Mon (2014), esta realidade não deverá ser vista exclusivamente como um problema, mas também como uma oportunidade de mudança, podendo, uma Educação Física bem planeada, constituir um remédio para aquela inatividade, desde que seja oferecida de forma a que os alunos sintam que estão a aprender e entendam o valor daquelas aprendizagens, encontrando aqui a razão e a motivação para as aulas. 
Assim, se queremos que os alunos passem do "jogo no ecrã" para os campos de jogos, a Educação Física terá de ser acompanhada de melhorias da qualidade dos processos de ensino e aprendizagem, designadamente pelo recurso a diferentes modelos de ensino que possam servir de apoio à transformação dos discursos e das respetivas práticas, assim como à reconfiguração dos papéis, das responsabilidades e das relações entre os seus atores (BATISTA; QUEIRÓS, 2015). É fundamental, portanto, que os alunos entendam as aprendizagens em Educação Física como significativas, para que autores como Doolittle et al. (2007), não se questionem sobre o valor e pertinência da disciplina enquanto obrigatória ao longo da escolaridade, em resultado da dificuldade dos professores conseguirem provar os benefícios concretos da sua ação a alunos, pais, colegas das outras áreas, órgãos de gestão das escolas e demais autoridades.

Neste sentido Crum $(1993,2017)$ afirma que a indefinição nas conceções de ensino na Educação Física, oscilando entre uma ideologia biologista, onde aquela disciplina é reduzida ao treino físico, e a pedagogista, onde assume o caráter de recreação desportiva, tem como resultado um processo de ensino-aprendizagem desfocado da aprendizagem e focado na aptidão física, na diversão ou no controlo disciplinar.

Por outro lado, por muita vontade que os professores de Educação Física tenham em implementar programas consequentes de ensino e aprendizagem, as resistências com que frequentemente se deparam quanto ao que tal exige dos alunos, quer da parte destes, quer dos seus progenitores e até mesmo da própria escola, levaos a privilegiarem os interesses dos estudantes, conseguindo assim a sua cooperação e, consequentemente, uma aula sem sobressaltos (BATISTA; QUEIRÓS, 2015).

A tentativa de justificar a Educação Física com base em valores extrínsecos em detrimento dos intrínsecos, dando-lhe um caráter utilitário, como é o caso da saúde em lugar do valor educativo em si mesmo (BATISTA; QUEIRÓS, 2015), não está a facilitar a vida nem a professores nem a alunos. Os primeiros porque não sabem o que privilegiar no seu ensino e os segundos porque veem as suas aprendizagens comprometidas.

Como afirmam Arévalo, Hernando e Mon (2014), um dos pontos fortes do currículo aberto e flexível é a capacidade de decisão dos professores. Cada profissional poderá escolher em função do contexto da escola, das características dos seus alunos, dos costumes, das modas, da sua formação, da sua capacidade de inovar, de estar atualizado, etc. O mais importante é ter claro que as aprendizagens são decisivas para os alunos, pelo que há que escolher os objetivos e os conteúdos com critério e com intencionalidade.

Num estudo de Valenzuela et al. (2019) sobre a perceção das aprendizagens em Educação Física, adquiridas ao longo da escolaridade obrigatória, de estudantes universitários portugueses e chilenos na via do ensino daquela área curricular, os autores concluíram que os alunos de ambas as nacionalidades foram incapazes de identificar claramente os saberes específicos adquiridos na disciplina e revelaram-se discordantes da forma como aquela é ensinada, justificando-o pela constante repetição de objetivos, conteúdos, estrutura das aulas e metodologias de ensino. 
Na mesma linha se enquadram os resultados obtidos por Lourenço e RibeiroSilva (2019) num estudo focado no ensino da Ginástica na escola, onde mais de $65 \%$ dos inquiridos (172 alunos do $1^{\circ}$ ano de licenciaturas em Ciências do Desporto em Portugal) afirmaram nunca terem abordado cerca de metade dos gestos técnicos previstos nos Programas Nacionais de Educação Física (PNEF) para aquela modalidade. Os mesmos manifestaram, ainda, terem gosto por Ginástica, mas desinteresse e desmotivação pelas aulas, justificando-o com a mesma repetividade encontrada por Valenzuela et al. (2019).

Também Fachada (2019) ${ }^{1}$, ao analisar os resultados das provas de aferição de Educação Física em 42 turmas (n estimado de 800 alunos) do $8^{\circ}$ ano de escolaridade de 2018, realizadas por 96.735 alunos portugueses, concluiu que quase um quarto destes não conseguiu alcançar os valores mínimos de aptidão aeróbica, medida num teste vai-vem com percursos de 20 metros. Ainda nestas provas, quase $40 \%$ dos alunos não realizou ou realizou com dificuldade os gestos técnicos de Badmínton, tendo o mesmo acontecido com mais de $70 \%$ na Ginástica e 65\% nos Jogos Desportivos Coletivos.

Estas provas de aferição, realizadas a meio dos ciclos de ensino e sem valor classificativo, têm por objetivo a obtenção de uma visão nacional sobre as aprendizagens dos alunos, para que se possam rever ou reforçar decisões no projeto da escola ou nas próprias políticas educativas, o que, face a estes resultados, nos parece haver muito para refletir.

Insistimos, no entanto, em que estes resultados não se sustentam nos PNEF, dado que o seu recorte aberto não serve de justificação para a não lecionação dos conteúdos previstos. Pelo contrário, permite, pela autonomia que dá às escolas e principalmente aos professores, no que respeita às decisões pedagógicas, que todos os alunos, através de diferentes matérias, diferentes modelos, diferentes técnicas e/ ou estratégias de ensino, possam adquirir os conhecimentos ali preconizados. Ideia que foi retomada quer nas Metas de Aprendizagem em Educação Física (ROCHA; COMÉDIA; MIRA; GUIMARÃES; 2011), nunca promulgadas, quer recentemente no Perfil dos Alunos à Saída da Escolaridade Obrigatória (PERFIL, 2017) e nas respetivas Aprendizagens Essenciais, conducentes à consecução daquele Perfil.

Numa apresentação muito sucinta destes dois últimos documentos, importa referir que no Perfil são apresentadas dez grandes Áreas de Competências, cujo desenvolvimento por parte dos alunos ao longo da escolaridade obrigatória, é considerado central, sendo aquelas transversais a todas as áreas curriculares, embora com amplitudes de desenvolvimento distintas, dependentes da especificidade de cada área de ensino. Ilustrando esta afirmação, a Educação Física contribuirá substancialmente para o desenvolvimento da Consciência e Domínio do Corpo e menos para Linguagens e Textos, e o inverso sucederá com as línguas.

Já as Aprendizagens Essenciais, que estão intimamente ligadas ao Perfil, constituem um denominador curricular comum de referência para a aprendizagem de todos os alunos, de acordo com o respetivo ciclo de ensino, mas com uma visão de

1 FACHADA, Miguel. Os Efeitos da Educação Física. In: FÓRUM INTERNACIONAL DAS CIÊNCIAS DA EDUCAÇÃO FÍSICA, 8. EDUCAÇÃO FÍSICA: Espaço e Identidade. Coimbra: FCDEFUC, 16-17 maio 2019. (comunicação oral, não publicado). 
continuidade e articulação vertical ao longo de toda a escolaridade obrigatória, que em Portugal é de doze anos.

Todos estes documentos se assumem como orientadores (e não uniformadores) na planificação, realização e avaliação do ensino e da aprendizagem em todas as áreas curriculares e, consequentemente, também em Educação Física.

Assim sendo, o recente esforço governamental na sua construção, visando a melhoria das aprendizagens, justifica o nosso interesse em perceber em que medida têm estado a ser adquiridos conhecimentos essenciais a uma prática desportiva autónoma, segura e continuada ao longo da vida, objetivos que sempre constaram dos PNEF, os quais desde 2001 (data da última revisão) continuam sendo estruturadores do ensino na Educação Física em Portugal.

\section{OBJETIVO DO ESTUDO}

Com este trabalho pretendemos perceber se a Educação Física está a ensinar, visando a aptidão física, na perspetiva da melhoria da qualidade de vida, saúde e bemestar e, ainda, no sentido de reforçar o gosto pela prática regular das atividades físicas e aprofundar a compreensão da sua importância como fator de saúde ao longo da vida e componente da cultura, na dimensão individual e social, desígnios constantes das Finalidades da disciplina, inscritas no respectivo PNEF (p.10) para o ensino secundário. Finalidades aquelas que surgem especificadas num conjunto de Objetivos, de entre os quais destacamos: i) Conhecer e interpretar os fatores de saúde e risco associados à prática das atividades físicas e aplicar as regras de higiene e de segurança; ii) Conhecer [...] diversos processos de elevação e manutenção da condição física de uma forma autónoma no seu quotidiano, na perspetiva da saúde, qualidade de vida e bem-estar; (PNEF, p.14)

Em suma, ao objetivo deste estudo está subjacente o interesse em percebermos a qualidade de aprendizagens essenciais a uma prática desportiva autónoma, segura e continuada ao longo da vida, na disciplina de Educação Física, mas também, a preocupação sobre a situação de potencial risco a que os indivíduos ficam expostos ao se decidirem por uma prática de exercício físico de forma autónoma, caso se verifiquem fragilidades ou mesmo ausência dos conhecimentos pressupostos.

\section{AMOSTRA}

Este estudo foi realizado com 150 estudantes do sexo masculino, no final da escolaridade obrigatória e candidatos a uma licenciatura em Ciências do Desporto, com uma média de idades de 18,40 anos $( \pm 1,45)$ e provenientes de 52 escolas públicas e privadas com ensino secundário, pertencentes a 15 distritos de Portugal, sendo a região centro-norte do país a mais representada. Os inquiridos tinham obtido uma classificação média de 16,6 valores na última avaliação em Educação Física, tendo $82,2 \%$ deles atingido uma nota igual ou superior a 16, num máximo possível de 20 valores, sendo que $92,6 \%$ afirmaram ser praticantes de, pelo menos, uma modalidade desportiva, dos quais $46,5 \%$ de nível nacional ou internacional. 
Importa também salientar a elevada formação académica dos progenitores, dos quais mais de $54 \%$ dos pais e $68 \%$ das mães possuíam formação igual ou superior ao ensino secundário e destes, $21 \%$ e $32 \%$, respetivamente, eram licenciados.

\section{MATERIAL E MÉTODO}

Construímos e aplicámos um questionário que designámos de Questionário de Conceções e Aprendizagens em Educação Física_Alunos (Q_CAEFA) composto por 3 partes. Uma primeira constituída por questões fechadas e de caracterização sociodemográfica dos participantes, cujos dados mobilizámos para a caraterização anteriormente apresentada. A segunda, composta por questões de escolha múltipla, com as quais se pretendia perceber a capacidade dos inquiridos em identificarem as Finalidades da Educação Física, assim como o grau de importância que atribuíam a cada uma delas. E ainda uma questão de escolha dicotómica (sim/não) sobre o nível de competência que cada indivíduo se reconhecia na elaboração de um plano elementar de prática, segura e autónoma, de exercício físico.

Por fim, uma terceira parte, também de escolha dicotómica (verdadeiro/ falso), composta por 25 afirmações sobre matéria de Educação Física. Estas foram construídas a partir dos conhecimentos preconizados nos vários documentos emanados do Ministério da Educação quanto aos conteúdos de ensino da disciplina, nomeadamente, Programas Nacionais de Educação Física (PNEF) para o ensino secundário, Perfil de Aluno à Saída da Escolaridade Obrigatória (PERFIL, 2017) e as respetivas Aprendizagens Essenciais.

Apesar dos conteúdos programáticos surgirem, nos PNEF, operacionalizados em três grandes domínios: I)Atividades Físicas, II)Aptidão Física e III) Conhecimentos, o nosso estudo incidirá sobretudo neste último domínio, dado que pretendemos estudar o contributo dos conhecimentos adquiridos na disciplina de Educação Física, com vista a uma prática autónoma e segura de exercício físico, ao longo da vida. Nesta lógica, as 25 afirmações surgem indexadas a seis dimensões que deduzimos daquele domínio e constantes nos documentos já referidos, a saber: 1) Estilo de vida saudável; 2) Composição/funcionamento corporal; 3) Formação pessoal e social; 4) Alimentação; 5) Doseamento da intensidade e duração do esforço; 6) Desenvolvimento de capacidades motoras; 7) Efeitos de uma prática de exercício físico; 8) Procedimentos face a situações de risco/lesão.

Para encontrarmos as 25 afirmações, procedemos à análise do conteúdo dos conhecimentos preconizados nos dois livros escolares de Educação Física para o ensino secundário, das duas maiores editoras do país, tendo por base as categorias anteriormente apresentadas, donde resultaram 62 itens.

Optámos por este procedimento dado que nestes livros encontramos aqueles grandes temas dos PNEF operacionalizados em subtemas, conteúdos e situações de ensino, muito próximas das aplicadas pelos professores de Educação Física nas respetivas aulas, o que, para além de nos orientar na estruturação dos itens dentro da cada categoria, também os tornou mais alinhados com a compreensão dos inquiridos.

Em seguida construímos afirmações, verdadeiras e falsas, sobre cada um daqueles itens, as quais foram enviadas a três professor especialistas na 
área, solicitando-lhes que assinalassem, para cada uma, se a consideravam ser fundamental, importante ou pouco relevante como conhecimento a dominar pelos alunos à saída da escolaridade obrigatória no sentido de manterem uma prática autónoma, segura e continuada de exercício físico ao longo da vida.

Construída a terceira parte do questionário, mobilizando unicamente as 25 afirmações que os três especialistas consultados consideraram unanimemente como fundamentais, passámos à validação (por pares) do conteúdo do questionário final, por três outros doutorados especialistas e do seu discurso, por seis estudantes com características etárias e académicas idênticas aos da nossa amostra e pertencentes a três escolas secundárias não participantes no estudo.

Incorporadas as alterações pontuais por estes sugeridas, procedemos à aplicação do instrumento, a qual coincidiu com o momento de prestação de provas de pré-requisitos dos candidatos à formação superior universitária, tendo os participantes respondidos depois de finalizarem as respetivas provas, de forma esclarecida, voluntária e anónima.

\section{ANÁLISE E DISCUSSÃO DOS RESULTADOS}

Dada a dimensão do questionário, optámos por neste primeiro momento apresentar apenas os dados resultantes da aplicação de uma estatística descritiva, concretamente, média, desvio padrão, frequências relativas e absolutas, para o que recorremos ao software Statistical Package for the Social Sciences, versão 24.

Assim sendo e tendo os resultados da primeira parte do questionário já sido apresentados aquando da caracterização dos participantes, passamos à apresentação dos resultados mais significativos da segunda parte.

Neste destacamos que, apesar da maior parte dos inquiridos ter reconhecido as Finalidades da Educação Física preconizadas nos PNEF, ainda existe uma percentagem significativa de indivíduos que Ihe atribui finalidades que nada têm a ver com as reais, a saber: $26 \%$ considera que aquela deverá ser um espaço essencialmente recreativo de modo a que contribua para a socialização dos alunos; $37 \%$ consideram ser sua finalidade o aperfeiçoamento dos jovens nas atividades físicas da sua preferência com vista a uma carreira competitiva e 30\% consideram ser finalidade da Educação Física assegurar o desenvolvimento de saberes e estratégias de sobrevivência, preparando para a entrada na vida adulta e no mercado de trabalho. Estes resultados sustentam-se nas ideias de Rivas e Mateos (2016), quando afirmam que os professores de Educação Física se focam mais no ensino dos valores do que na consecução dos objetivos específicos da disciplina, resultando numa escassez de conhecimentos, assim como, nas de Crum, (2017) e Souza et al. (2017), que defendem que a maior parte das aulas tende a oscilar entre a diversão ou o treino, tornando possível a existência de alunos que, ao longo da sua escolaridade, nunca se tenham sentido em processo de aprendizagem.

Tal é ainda mais notório nesta população maioritariamente atleta, para quem a Educação Física só poderá concorrer com o impacto do treino nas suas vidas, se se assumir como uma área de ensino e neste âmbito lhes ensinar algo de significativo para o momento e para a vida. 
Esta relevância do treino é confirmada quando mais de $90 \%$ dos inquiridos considerou ter conhecimentos para a elaboração de um plano elementar de exercício físico para uma prática autónoma ao longo da vida, de entre os quais mais de $75 \%$ afirmou ter aprendido no contexto do treino e os restantes nas aulas de Educação Física.

Passando à terceira parte do questionário, que, como já referimos, era composta por 25 afirmações indexadas às oito categorias anteriormente apresentadas e de resposta dicotómica (verdadeiro/falso), optámos por apresentar apenas as categorias e itens/indicadores mais relevantes quanto à elevada percentagem de respostas erradas, não deixando, no entanto, de contabilizar a totalidade dos dados no cálculo da média de erro por categoria (tabela 1).

Tabela 1 - Categorias/afirmações com percentagem mais significativas de respostas erradas

\begin{tabular}{|c|c|c|c|}
\hline CATEGORIA & AFIRMAÇÕES & ${ }^{1}$ Erro \% & $\begin{array}{c}{ }^{2} \text { Média erro } \\
\text { p/categ. }\end{array}$ \\
\hline \multirow{3}{*}{$\begin{array}{l}\text { Composiçãol } \\
\text { funcionamento } \\
\text { corporal }\end{array}$} & $\begin{array}{l}\text { Um jovem adulto (saudável) deverá ter uma } \\
\text { frequência cardíaca (FC) não superior a } 75 \\
\text { pulsações por minuto. }\end{array}$ & $26,4 \%$ & \multirow{3}{*}{$25,95 \%$} \\
\hline & $\begin{array}{l}\text { A FC máxima de um jovem adulto (saudável) é de } \\
\text { aproximadamente } 220 \text { pulsações por minuto. }\end{array}$ & $22,4 \%$ & \\
\hline & $\begin{array}{l}\text { De acordo com a Organização Mundial de Saúde, a } \\
\text { obesidade e as doenças que Ihe estão associadas, } \\
\text { são atualmente uma grande preocupação mundial. }\end{array}$ & $40,8 \%$ & \\
\hline $\begin{array}{l}\text { Doseamento da } \\
\text { intensidade e } \\
\text { duração do esforço }\end{array}$ & $\begin{array}{l}\text { As atividades anaeróbias estão associadas a } \\
\text { esforços prolongados, de intensidade baixa ou } \\
\text { moderada. }\end{array}$ & $53,7 \%$ & $21,62 \%$ \\
\hline \multirow{2}{*}{$\begin{array}{l}\text { Desenvolvimento } \\
\text { de capacidades } \\
\text { motoras }\end{array}$} & $\begin{array}{c}\text { A aptidão física é a capacidade para executar as } \\
\text { tarefas diárias de forma ativa e vigorosa, sem } \\
\text { acumular fadiga excessiva. }\end{array}$ & $29,7 \%$ & \multirow{2}{*}{$33,30 \%$} \\
\hline & $\begin{array}{l}\text { A velocidade depende essencialmente do tipo de } \\
\text { treino efetuado, não estando relacionada com a } \\
\text { herança genética das pessoas. }\end{array}$ & $50,7 \%$ & \\
\hline \multirow{3}{*}{$\begin{array}{l}\text { Efeitos de uma } \\
\text { prática de exercício } \\
\text { físico }\end{array}$} & $\begin{array}{l}\text { Praticar exercício físico permite transformar a } \\
\text { massa gorda em massa muscular. }\end{array}$ & $90 \%$ & \multirow{3}{*}{$72,50 \%$} \\
\hline & $\begin{array}{l}\text { A realização de exercícios localizados (por } \\
\text { exemplo, fazer abdominais) permite perder gordura, } \\
\text { em primeiro lugar, nas zonas que estão a ser } \\
\text { solicitadas. }\end{array}$ & $77,2 \%$ & \\
\hline & $\begin{array}{l}\text { Realizar exercício físico com maior quantidade } \\
\text { de roupa vestida (por exemplo, impermeável ou } \\
\text { térmica) ajuda a perder gordura mais rapidamente. }\end{array}$ & $50,3 \%$ & \\
\hline \multirow{2}{*}{$\begin{array}{l}\text { Procedimentos } \\
\text { face a situações de } \\
\text { risco/lesão }\end{array}$} & $\begin{array}{l}\text { Se durante a prática físico-desportiva sentir cãibras } \\
\text { (contração dolorosa e involuntária de um ou vários } \\
\text { músculos) deverá fazer aplicação de gelo na zona } \\
\text { afetada. }\end{array}$ & $55,7 \%$ & \multirow[b]{2}{*}{$48,50 \%$} \\
\hline & $\begin{array}{l}\text { Se durante a prática físico-desportiva sentir uma } \\
\text { lesão muscular (dor intensa num determinado ponto } \\
\text { do músculo afetado) deverá parar o exercício, } \\
\text { massajar a zona afetada e aplicar calor (por } \\
\text { exemplo, com um saco de água quente). }\end{array}$ & $76,5 \%$ & \\
\hline
\end{tabular}

${ }^{1}$ Percentagem de respostas erradas por item; ${ }^{2}$ Média das percentagens de erro na categoria Fonte: Os autores 
Assim sendo, podemos constatar que os participantes apresentam significativas fragilidades de conhecimentos relativamente a: i) Doseamento da intensidade e duração do esforço, com $21,62 \%$ de média de erro no total dos itens/indicadores da categoria e de $53,7 \%$ de respostas incorretas quanto a conhecimentos sobre as atividades anaeróbias; ii) Composição e funcionamento corporal, com 25,95\% de média de erro na categoria e, dentro desta, $40,8 \%$ de respostas erradas no item relativo a conhecimentos sobre os índices de massa corporal; iii) Desenvolvimento de capacidades motoras, onde a média do erro na categoria foi de $33,3 \%$, com $50,7 \%$ de erro no item sobre conhecimentos acerca do desenvolvimento da velocidade.

Com lacunas de conhecimentos ainda mais graves apresentam-se as categorias sobre Procedimentos face a situações de risco/lesão, com 48,5\% de média de erro e $76,5 \%$ de insucesso nas respostas no item respeitante a procedimentos face a lesão, e a categoria Efeitos de uma prática de exercício físico, com 72,5\% de média de erro, apresentando esta dois dos seus itens/indicadores com elevada percentagem de erro. O primeiro referente à relação entre a prática de exercício, a perda de massa gorda e o ganho de massa muscular (90\%) e o segundo, respeitante aos efeitos da realização de exercícios localizados $(77,2 \%)$.

Assim, apesar das elevadas classificações na disciplina de Educação Física, da quase totalidade dos indivíduos serem ou terem sido praticantes a um nível elevado de, pelo menos, uma modalidade desportiva e de afirmarem dominarem os conhecimentos necessários à elaboração de um programa elementar de exercício físico para uma prática autónoma, segura e continuada ao longo da vida, os resultados permitem-nos perceber que são grandes as lacunas sobre conhecimentos básicos que aquele planeamento implicaria. Tal como é grande o risco a que ficam expostos caso se decidam por uma prática de exercício físico auto conduzida e auto controlada.

A acrescentar a esta realidade temos ainda o facto de uma significativa maioria dos inquiridos ter atribuído a aquisição daqueles conhecimentos ao contexto de treino, o que nos permite concluir que, para além de não terem consciência sobre o seu desconhecimento, ainda desvalorizam a Educação Física na sua formação desportiva.

Ou seja, os alunos não sabem que não sabem, mas sabem que não o aprenderam na Educação Física, o que nos reconduz, quer a Batista e Queirós (2015), quando afirmam que a pressão que a saúde exerce sobre a Educação Física a vem instrumentalizando para finalidades alheias da educação, colocando-a numa posição de vulnerabilidade ao responsabilizá-la por algo que ela não pode assegurar, quer a Crum (1993), quando defende a necessidade de que as aulas de Educação Física sejam verdadeiras atividades de ensino-aprendizagem, como função decisiva daquela disciplina.

Por outro lado, sendo, como vimos, grande parte dos participantes oriundos de famílias com formação académica elevada, poder-se-ia esperar que esta desvalorização da Educação Física não fosse tão expressiva, o que nos leva a considerar não serem evidentes para os progenitores as aprendizagens que os seus educandos adquirem na disciplina. 
Contudo, estes resultados podem não ser tão negativos como à primeira vista poderão parecer, já que confirmam a existência de um espaço para uma Educação Física que ensine para a vida, dado que ficou patente que foram estes os conhecimentos que os inquiridos não adquiriram, nem mesmo no treino.

Parece-nos que tal só poderá ser conseguido através de um ensino significativo, situado (BLÁZQUEZ, 2016) e intencional, sendo fundamental que os seus conteúdos tenham sentido para os alunos, devendo ser ensinados o mais próximo possível da sua forma final, situados num contexto e com objetivos bem determinados.

Apesar das escolas europeias terem atualmente um conjunto de condições físicas que lhes permite uma oferta diversificada e ajustada de formação na atividade física (ONOFRE, 2017), a Educação Física tem tido dificuldade em libertar-se do seu estigma de subalternidade relativamente às outras áreas curriculares, sendo frequentemente considerada pelos outros professores, como um tempo onde os alunos podem descarregar as energias acumuladas nas disciplinas "teóricas".

Contudo, a responsabilidade de alterar esta visão está do lado de quem fez do ensino da Educação Física a sua profissão, fazendo parte deste compromisso a investigação, a autoformação e a constante busca de soluções para melhor ensinar.

Como vimos atrás, o modelo tradicional de ensino, essencialmente analítico, de reprodução, quase sempre descontextualizado e sem uma intenção subjacente, já deu provas de que não responde aos desafios de uma educação do século XXI, onde, como diz Blázquez (2016), estamos a ensinar jovens para que dentro de 10 a 15 anos venham a ser cidadãos válidos na "sua" sociedade, ou seja, para o desconhecido. Assim sendo, o que importa é ensiná-los a aprender, apostando em novas formas de ensino onde o aluno seja empoderado da e pela sua aprendizagem.

Para que este processo seja bem-sucedido é também fundamental que os alunos "levem a Educação Física para casa", despertando o interesse e envolvimento dos seus encarregados de educação, o que só é possível se os alunos aprenderem, se tiverem consciência dessa aprendizagem e se tiverem responsabilidade nela.

\section{CONSIDERAÇÕES FINAIS}

Não negando a relevância da qualidade do ensino dos professores e a predisposição para a aprendizagem dos alunos, na qualidade das suas aprendizagens, que este estudo não se refere, uma reflexão se impõe sobre estes resultados, baseada essencialmente na interrogação sobre quais as aprendizagens adquiridas pelos alunos após doze anos de escolaridade obrigatória e de um mínimo de oito de Educação Física, percurso idêntico apenas ao da disciplina de Língua Portuguesa.

Reafirmando Graça (2012), a dualidade ideológica pedagogia-biologia, que insiste em (re)orientar a Educação Física, parece estar a conduzir os professores a um ziguezague entre a tentativa de que os alunos aprendam os conteúdos duma disciplina cujo objeto é o Desporto e a tentativa de lhes promover alterações morfológicas e fisiológicas, sabendo-se que tal dificilmente será conseguido de 
forma significativa, face ao reduzido tempo efetivamente disponível para a prática e à baixa intensidade das mesmas, muitas vezes em consequência das dificuldades de desempenho dos alunos.

Ainda segundo o mesmo autor, apesar da curta duração e baixa intensidade da atividade física naquelas aulas, que só por si justificariam a não atribuição de objetivos de saúde à Educação Física, tal não deixa de fazer com que os professores se considerem responsáveis por incutir nos alunos hábitos para uma vida ativa e saudável, descentrando o objetivo das aprendizagens (GRAÇA, 2012).

O caráter aberto dos PNEF, atribuindo ao professor um largo espectro de decisões, funciona aqui em seu desfavor, já que não se revela orientador do rumo a dar ao seu processo de ensino-aprendizagem.

Antes de terminarmos esta reflexão relembramos Carreiro da Costa (2005), quando há mais de uma década afirmou: "Recentemente têm-se levantado vozes quanto à necessidade de se repensar a Educação Física, quanto ao seu papel e a forma como é pensada na escola. Isto baseado nas diversas formas de ver a Educação Física.", o que nos parece conservar a atualidade face às recentes afirmações de Rivas e Mateos (2016) sobre o papel dos professores de Educação Física, considerando que aqueles, perdidos nos seus objetivos, não se focam no ensino dos objetivos específicos da disciplina, levando a uma escassez de conhecimentos sobre a matéria.

Ou seja, "[...] existe um currículo retórico e um currículo que reflete as práticas atuais por detrás das portas das salas de aulas ou do ginásio" (CARREIRO DA COSTA, 2005), estando este último estreitamente dependente da profissionalidade do professor, entendida tal como Roldão $(2005,2008)$ como especificidade da função, saber específico, poder de decisão e pertença a um grupo coletivo.

Certo é, que os conhecimentos adquiridos pelos alunos em Educação Física, ao longo da escolaridade obrigatória, ficam muito aquém do desejável, pelo que há que detetar os motivos e intervir diretamente neles. Processo em que a produção documental poderá ajudar, mas apenas se for acompanhada pela formação inicial e continuada de professores, no sentido dum ensino através de métodos e modelos mais "democráticos" que favoreçam a autonomia do aprendente e o responsabilize pela sua aprendizagem, porque também o integra no processo.

Concluindo, a preocupação da parte das entidades oficiais com a qualidade das aprendizagens do alunos em geral, onde se incluem as aprendizagens em Educação Física, e os esforços por estas desenvolvidos na produção de documentos orientadores do processo ensino-aprendizagem conducentes ao desenvolvimento das competências consideradas essenciais, embora os consideremos fulcrais, também nos parecem muito limitados no seu sucesso enquanto as alterações não acontecerem ao nível da sala de aula. Até lá a Educação Física vai continuar a não formar, pelo menos de forma plena, indivíduos fisicamente cultos, apesar de tal ser um desígnio expresso, há mais de duas décadas, nos Programas Nacionais de Educação Física. 


\section{REFERENNCIAS}

ARÉVALO, Carles; HERNANDO, Meritxell; MON, Carles. Una Educación Física para la vida: recursos prácticos para un aprendizaje funcional. Barcelona: Editorial INDE, 2014. p.14.

BATISTA, Paula; QUEIRÓS, Paula. (Re)colocar a aprendizagem no centro de Educação Física. In: MARQUES, António; BATISTA, Paula; QUEIRÓS, Paula.

Desafios renovados para a aprendizagem em Educação Física. Porto, Ed. FADEUP, 2015. p. 29-43.

BLÁZQUEZ, Domingo. Métodos de enseñanza en Educación Física, Barcelona: Editorial INDE, 2016. p.7-15

CAMPOS, Paul. The Obesity Myth: Why America's Obsession with Weight is Hazardous to Your Health. New York: Gothan, 2004. p.6

CARREIRO DA COSTA, Francisco. Changing the Curriculum does not Mean Changing Practices at School: the impact of teachers' beliefs on curriculum implementation. In: CARREIRO DA COSTA, Francisco; CLOES, Marc; VALEIRO, Miguel. The art and Science of Teaching in Physical Education and Sport. Lisboa: Ed. FMH, 2005. p. 257-277.

CRUM, Bart. A Crise de Identidade da Educação Física: Ensinar ou não Ser, eis a Questão. Boletim da Sociedade Portuguesa de Educação Física, n.7/8, p.133-148, 1993.

CRUM, Bart. How to win the battle for survival as a school subject? Reflections on justifications, objectives, methods and organization of PE in schools of the $21^{\text {st }}$ century. RETOS, n.31, p. 238-244, 2017.

DOOLITTLE, Jennifer et al. Importance of Student Social Behavior in the Mission Statements, Personnel Preparation Standards, and Innovation Efforts of State Departments of Education. The Journal of Special Education v. 40, n. 4, p.239-245, 2007.

GARD, Michael; WRIGHT, Jan. The obesity epidemic: science, morality, and Ideology. London: Routledge, 2005. p.3.

GRAÇA, Amândio. Sobre as questões do quê ensinar e aprender em Educação Física, In: MESQUITA, Isabel; BENTO, Jorge. Professor de Educação Física: Fundar e dignificar a profissão. Belo Horizonte: Casa da Educação Física, 2012. p. 93-117.

LOURENÇO, Carla; RIBEIRO-SILVA, Elsa. Ginástica na escola: o que e o como se ensina ao longo da escolaridade obrigatória, Journal of Sport Pedagogy \& Research, Special Edition, v. 5, n. 2, p.32, 2019.

MALHOTRA, Aseem;, NOAKES, Timothy, PHINNEY, Stephen. It is time to bust the myth of physical inactivity and obesity: you cannot outrun a bad diet. British Journal of Sports Medicine, v. 49, p.967-968, 2015.

PERFIL dos Alunos à Saída da Escolaridade Obrigatória. Lisboa: Ministério da Educação/ Direção-Geral da Educação, 2017. Disponível em: https://dge.mec.pt/sites/default/files/ Curriculo/Projeto_Autonomia_e_Flexibilidade/perfil_dos_alunos.pdf. Acesso em: 14 jun.2020.

MORENO-DOÑA, Alberto; RIVERA-GARCIA, Enrique; TRIGUEROS-CERVANTES, Carmen. La Educación Física en Chile: un análisis de las creencias del profesorado de la enseñanza primaria y secundaria, Movimento, v. 20, n.esp., p.81-96, 2014. 
ONOFRE, Marcos. Qualidade da Educação Física como Essência da Promoção duma Cidadania Ativa e Saudável. RETOS, n. 31, p. 328-333, 2017.

PNEF. PROGRAMAS NACIONAIS DE EDUCAÇÃO FÍSICA. Ministério da Educação de Portugal. Departamento Do Ensino Secundário, 2001. Disponível em: https://www.dge. mec.pt/sites/default/files/Secundario/Documentos/Documentos_Disciplinas_novo/Curso Ciencias Tecnologias/Educacao Fisica/ed fisica 10 11 12.pdf. Acesso em: 18 jun. 2020

RIVAS, María; MATEOS, Maria Espada. Actitud del Profesorado de Educación Física Frente al Aprendizaje Cooperativo. Movimento, v. 22, n. 2, jul./set. p.861-876, 2016.

ROCHA, Leonardo; COMÉDIAS, João; MIRA, Jorge; GUIMARÃES, Mário. Metas de Aprendizagem de Educação Física Ensino Secundário. Lisboa: Direção Geral da Educação, 2011. Disponível em: https://cnapef.files.wordpress.com/2012/12/ ensinosecundc3a1rio-metasaprendizagem-educac3a7c3a3o-fc3adsica.pdf. Acesso em: 18 jun. 2020

ROLDÃO, Maria do Céu. Formação de professores baseada na investigação e na prática reflexiva. In: PORTUGAL. Ministério da Educação. Direção Geral dos Recursos Humanos da Educação (org.). Presidência Portuguesa do Conselho da União Europeia: desenvolvimento profissional de professores para a qualidade e para a equidade da aprendizagem ao longo da vida. Lisboa: Ministério da Educação, 2008. p.40-49

ROLDÃO, Maria do Céu. Profissionalidade docente em análise: especificidades dos ensinos superior e não superior. Nuances: Estudos Sobre Educação, ano XI, v. 12, n. 13, p.105-126, jan./dez. 2005.

SOUZA, Jeferson et al. As crenças de graduandos em Educação Física sobre o ensino dos esportes, Movimento, v.23, n.1, p. 133-146, 2017.

VALENZUELA, Luis, RIBEIRO-SILVA, Elsa, HIDALGO, Felipe, CISTERNAS, Constanza. La percepción de los estudiantes que ingresan a la carrera de Pedagogía en Educación Física sobre sus saberes disciplinares: estudio comparativo entre Chile y Portugal. In: RUIZ-JUAN, Francisco; GONZÁLEZ JURADO, José Antonio; CALVO LLUCH, Africa del XIII CONGRESO INTERNACIONAL FEADEF SOBRE LA ENSEÑANZA DE LA EDUCACIÓN FÍSICA Y EL DEPORTE ESCOLAR, 13. y CONGRESO RED GLOBAL, 2. , 20-23 jun. 2019. Libro de actas..., Sevilla: FEADEF-APEF, 2019. p.96-105.

WORLD HEALTH ORGANIZATION. Country Profiles on Nutrition, Physical Activity and Obesity in the $\mathbf{5 3}$ WHO European Region Member States. Copenhague: World Health Organization Regional Office for Europe, 2013. p.7-10. 